\title{
A summary of the Pan-Canadian framework on sexually-transmitted and blood-borne infections
}

\author{
Centre for Communicable Diseases and Infection Control ${ }^{\text {* }}$
}

\begin{abstract}
Sexually-transmitted and blood-borne infections (STBBI) remain a significant health concern in Canada and around the world. To guide Canada's efforts to reduce the health impact of STBBI and to contribute to global efforts, a PanCanadian framework was developed and has been endorsed by federal, provincial and territorial ministers of health. The framework sets out an overarching and comprehensive approach to address STBBI. It has an integrated approach given the shared common risk factors, transmission routes, and affected populations. The framework establishes a vision for Canada where STBBI are rare and people living with STBBI receive the care and support they need. The success of the framework will be measured against the global STBBI targets and progress towards these strategic goals: reduce the incidence of STBBI in Canada; improve access to testing, treatment, and ongoing care and support; and reduce stigma and discrimination that create vulnerabilities to STBBI. The framework is composed of four interconnected pillars that span the continuum of STBBI care: prevention, testing, initiating care and treatment, and ongoing care and support. The framework recognizes that the creation of an enabling environment that includes interrelated legal, social, cultural, physical, and structural conditions supports successful STBBI programs, policies and actions. Through this framework, Canada is unifying and communicating a common approach to addressing STBBI while respecting the flexibility required by jurisdictions and sectors to address different needs and priorities. As outlined in the Pan-Canadian framework, federal, provincial, and territorial governments will develop indicators and targets for Canada that will permit them to measure Canada's progress and guide their respective priorities for all pillars of the framework.
\end{abstract}

\author{
Affiliation \\ 1 Public Health Agency of Canada, \\ Ottawa, ON
}

*Correspondence: ccdic-clmti@ phac-aspc.gc.ca

Suggested citation: Centre for Communicable Diseases and Infection Control. A summary of the Pan-Canadian framework on sexually-transmitted and blood-borne infections. Can Commun Dis Rep 2018;44(7/8):179-81. https://doi.org/10.14745/ccdr.v44i78a05

Keywords: sexually-transmitted and blood-borne infections, framework, Canada

\section{Introduction}

Sexually-transmitted and blood-borne infections (STBBI) remain a significant health concern in Canada even though they are largely preventable, treatable and, in many cases, curable. Rates of certain STBBI continue to rise in Canada and global momentum to eliminate new infections is building. To this end, Canada has endorsed the United Nations Sustainable Development Goals, as well as the Joint United Nations Programme on HIV/ AIDS (UNAIDS), and the World Health Organization's (WHO) global health sector strategies to address HIV, viral hepatitis and sexually-transmitted infections. These goals and strategies call on countries to work towards the elimination of STBBI as a public health concern by 2030 (1).

To guide Canada's efforts to reduce the health impact of STBBI and to contribute to global efforts, a Pan-Canadian framework titled 'Reducing The Health Impact of Sexually-Transmitted and Blood-Borne Infections in Canada by 2030: A Pan-Canadian Framework for Action' was developed by the Public Health Agency of Canada and has been endorsed by federal, provincial and territorial ministers of health (2). This article is a summary of the full report.

\section{The state of STBBI in Canada}

In Canada, the number of newly diagnosed HIV and hepatitis C virus $(\mathrm{HCV})$ infections has remained relatively stable nationally in recent years, though there are variations at the regional level and among specific communities. An estimated 65,000 people were living with HIV in Canada at the end of 2014, of whom an estimated $20 \%$ were unaware of their status (2). Gay, bisexual and other men who have sex with men represented approximately $2.5 \%$ of the male population (15 years and older) and yet accounted for almost $50 \%$ of those living with HIV infection and more than 50\% of new infections in Canada in 2014 (3). As of 2011, an estimated 221,000 to 246,000 Canadians had a chronic HCV infection, of whom an estimated $44 \%$ were unaware of their status (4).

The numbers of newly diagnosed chlamydia, gonorrhea, and syphilis infections have also increased consistently since the mid1990s, despite numerous public health interventions designed to prevent, diagnose, and treat these infections (5). Between 2005 and 2014, there was a 49\% increase in the reported rate of chlamydia, a $61 \%$ increase in the reported rate of gonorrhea and a $95 \%$ increase in the reported rate of syphilis (6).

Canada has made progress in areas such as improving access to innovative treatments, creating strong surveillance 
systems to monitor infections, and building the capacity of community-based organizations. However, despite having the tools and having made some progress, there continues to be an unacceptable number of new infections in Canada. The time is right for Canada to foster a new approach to reduce new infections, improve health outcomes, and contribute to global efforts.

\section{An integrated approach}

In 2016 and 2017, concrete actions that could have a significant impact on rates of STBBI in Canada were identified through online surveys and in-person meetings with a broad range of partners and stakeholders, including people living with HIV and hepatitis, people from key populations, representatives of First Nations, Inuit and Métis communities and organizations, clinicians and other health professionals, community-based and civil society organizations, researchers, provincial and territorial governments, and representatives of the pharmaceutical industry. This input informed the framework through an iterative process.

The framework sets out an overarching and comprehensive approach to address STBBI. Canada has been evolving towards an integrated approach given the shared common risk factors, behaviours for transmission, and transmission routes across $\mathrm{STBBI}$, as well as the key populations affected by them. At the same time, it is recognized that infection-specific approaches are still appropriate in certain circumstances or communities. It is expected that partners and stakeholders across the country will look to the framework to inform their work. A collaborative approach will be required to succeed since one sector alone is not enough to reduce the health impact of STBBI.

\section{Pan-Canadian framework on STBBI}

The framework establishes a vision for Canada where STBBI are rare and people living with $\mathrm{STBBI}$ receive the care and support they need. The success of the framework will be measured against the global STBBI targets and progress towards these targets will support the following broader strategic goals for Canada:

- $\quad$ Reduce the incidence of STBBI in Canada

- Improve access to testing, treatment, and ongoing care and support

- $\quad$ Reduce stigma and discrimination that create vulnerabilities to STBBI

A set of guiding principles were adopted within the framework to help inform the collective action required to address STBBI in Canada (Table 1).

The framework is composed of four interconnected pillars that span the continuum of STBBI care:

- Prevention promotes sexual health knowledge, changes attitudes and behaviours, as well as supports the uptake of existing and emerging prevention interventions (e.g. HIV pre-exposure prophylaxis, vaccines);

- Testing promotes normalized routine offer of tests, new point-of-care testing, and addresses barriers to access testing;

- Initiation of care and treatment promotes timely care and treatment and the uptake of new medications for all populations; and
Table 1: Guiding principles of the 2018 Pan-Canadian Framework to reduce to reduce STBBI (2)

\begin{tabular}{|c|c|}
\hline $\begin{array}{l}\text { Guideline } \\
\text { principle }\end{array}$ & Definition \\
\hline $\begin{array}{l}\text { Meaningful engagement } \\
\text { of people living with HIV } \\
\text { and viral hepatitis and } \\
\text { key populations }\end{array}$ & $\begin{array}{l}\text { People living with HIV and viral hepatitis and key } \\
\text { populations are meaningfully engaged in the } \\
\text { development and implementation of policies and } \\
\text { programs that affect them. }\end{array}$ \\
\hline $\begin{array}{l}\text { Moving towards truth } \\
\text { and reconciliation }\end{array}$ & $\begin{array}{l}\text { Policies and programs to address STBBI among } \\
\text { Indigenous Peoples are developed by and with } \\
\text { First Nations, Inuit and Métis peoples through } \\
\text { a relationship grounded in mutual respect and } \\
\text { rooted in an understanding and recognition of } \\
\text { and responsiveness to the ongoing impacts of } \\
\text { colonization, health and social consequences of } \\
\text { residential schools, structural inequities and systemic } \\
\text { racism. }\end{array}$ \\
\hline Integrated approach & $\begin{array}{l}\text { Interventions and programs are designed to address } \\
\text { the complexity and interrelated nature of risk factors } \\
\text { and transmission routes for STBBI while recognizing } \\
\text { that disease-specific approaches may be appropriate } \\
\text { in some cases. }\end{array}$ \\
\hline Cultural relevance & $\begin{array}{l}\text { Policies and programs to address STBBI reflect and } \\
\text { respect cultural realities and practices while ensuring } \\
\text { the safety of individuals and communities. }\end{array}$ \\
\hline Human rights & $\begin{array}{l}\text { All people, regardless of their sexual orientation, } \\
\text { race, culture, gender, abilities, or personal practices, } \\
\text { are important and their human rights are recognized, } \\
\text { respected and promoted. }\end{array}$ \\
\hline Health equity & $\begin{array}{l}\text { All people, regardless of sex, gender, race, income, } \\
\text { sexual orientation, geographic location, status, } \\
\text { age or culture, have equitable access to quality } \\
\text { information and services from qualified health } \\
\text { professionals and other front-line providers. }\end{array}$ \\
\hline Multi-sectoral approach & $\begin{array}{l}\text { Multi-sectoral and multi-disciplinary approaches } \\
\text { to prevention and care are embraced to improve } \\
\text { collaboration and ensure interventions acknowledge } \\
\text { the whole individual and their wellness needs. }\end{array}$ \\
\hline $\begin{array}{l}\text { Evidence-based policy } \\
\text { and programs }\end{array}$ & $\begin{array}{l}\text { Interventions and programs are consistently } \\
\text { developed with, and guided by, the most recent } \\
\text { surveillance data, research and other evidence. }\end{array}$ \\
\hline
\end{tabular}

- Ongoing care and support promotes efforts to retain and reengage into care those who have been affected by STBBI, and includes the development of "wrap-around", interdisciplinary, multi-sectoral care models that incorporate STBBI services into primary care.

Further to the core pillars, the framework recognizes that the creation of an enabling environment is critical to the success of the actions under all core pillars of the framework. An enabling environment creates the conditions needed to ensure equitable coverage, to increase the uptake of services, and to improve the quality of health services. This includes interrelated legal, social, cultural, physical, and structural conditions that support successful STBBI programs, policies, and actions. An outline of the framework is noted in Figure 1.

The framework identifies 26 opportunities for action spanning across the pillars including the enabling environment that can be used to inform actions by people from key populations such as: Indigenous leadership/communities, civil society, health professionals, professional associations and licensing bodies, the private sector, and all levels of government. Lastly, the framework also recognizes surveillance, research, knowledge mobilization, and monitoring and evaluation as being important cross-cutting activities. 
Figure 1: A Pan-Canadian Framework to reduce health impact of STBBls in Canada

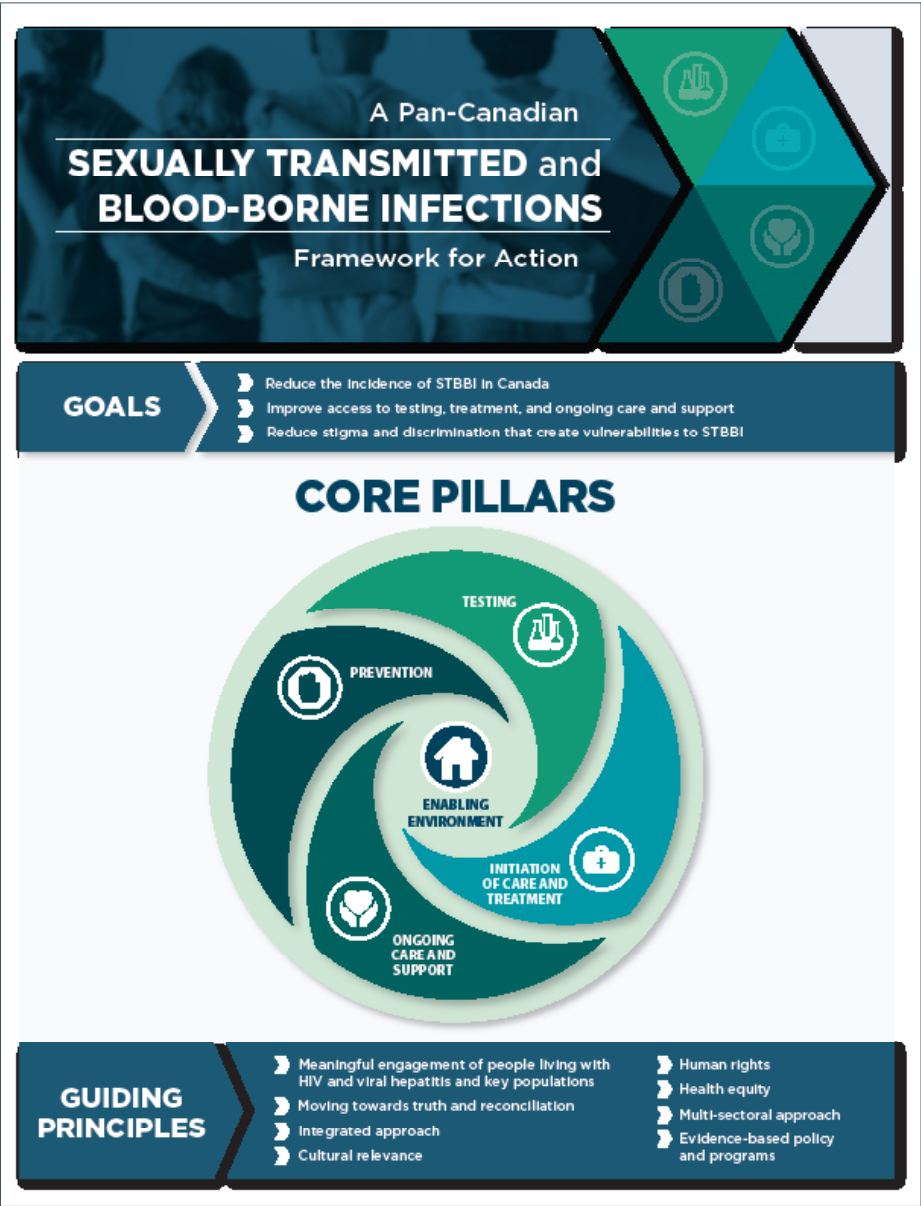

\section{Conclusion and next steps}

Through the Pan-Canadian framework, Canada is unifying and communicating a common approach to addressing STBBI while respecting the flexibility required by jurisdictions and sectors to address different needs and priorities. Federal, provincial, and territorial governments will develop indicators and targets for Canada that will permit them to measure Canada's progress and guide their respective priorities for all pillars of the framework.

The Government of Canada is developing an implementation plan that will identify specific actions to be undertaken by the federal government over the next five years that will help contribute to the elimination of STBBI and to achieve the strategic goals as set out in the framework.

\section{Acknowledgements}

The Public Health Agency of Canada would like to thank all those who contributed their time and expertise to the development of Reducing The Health Impact of Sexually-Transmitted and Blood-Borne Infections in Canada by 2030: A Pan-Canadian Framework for Action.

\section{References}

1. World Health Organization. Global Health Sector Strategy on HIV for 2016-2021 - Towards ending AIDS. Geneva: WHO; 2016. http://apps.who.int/iris/bitstream/handle/10665/246178/ WHO-HIV-2016.05-eng.pdf;jsessionid=93E5E1278057A10524 09B8802187C799? sequence $=1$

2. Public Health Agency of Canada. Reducing The Health Impact of Sexually-Transmitted and Blood-Borne Infections in Canada by 2030: A Pan-Canadian Framework for Action https://www.canada.ca/en/public-health/services/infectiousdiseases/sexual-health-sexually-transmitted-infections/reportspublications/sexually-transmitted-blood-borne-infectionsaction-framework.html

3. Public Health Agency of Canada. Summary: Measuring Canada's progress on the 90-90-90 HIV targets. Ottawa (ON): PHAC; 2016. https://www.canada.ca/en/public-health/services/ publications/diseases-conditions/summary-measuring-canadaprogress-90-90-90-hiv-targets.html

4. Public Health Agency of Canada. Summary: Estimates of HIV incidence, prevalence and proportion undiagnosed in Canada, 2014. Ottawa (ON): 2015. https://www.canada.ca/en/publichealth/services/publications/diseases-conditions/summaryestimates-hiv-incidence-prevalence-proportion-undiagnosedcanada-2014.html

5. Trubnikov M, Yan P, Archibald C. Estimated prevalence of Hepatitis C Virus infection in Canada, 2011. Can Commun Dis Rep 2014 Dec;40(19):429-36. PubMed (https://www.ncbi.nlm. nih.gov/pubmed/29769874)

6. Public Health Agency of Canada. Report on sexually transmitted infections in Canada: 2013 - 2014. Ottawa: PHAC; 2017. https://www.canada.ca/en/public-health/services/ publications/diseases-conditions/report-sexually-transmittedinfections-canada-2013-14.html 